\title{
Evaluation of Microbial Products for Management of Powdery Mildew on Summer Squash and Cantaloupe in Florida
}

Shouan Zhang, Tropical Research and Education Center, University of Florida, IFAS, Homestead 33031; Gary E. Vallad, Gulf Coast
Research and Education Center, University of Florida, IFAS, Wimauma 33598; Thomas L. White, Tropical Research and Education
Center, University of Florida, IFAS, Homestead; and Cheng-Hua Huang, Gulf Coast Research and Education Center, University of Florida, IFAS, Wimauma

\begin{abstract}
Zhang, S., Vallad, G. E., White, T. L., and Huang, C.-H. 2011. Evaluation of microbial products for management of powdery mildew on summer squash and cantaloupe in Florida. Plant Dis. 95:461-468.

Powdery mildew, caused by Podosphaera xanthii (syn. Sphaerotheca fuliginea auct. p.p.), is a serious and frequently occurring disease of cucurbits worldwide. Efficacy of four microbial products (i.e., Actinovate AG, Companion, BU EXP 1216C, and BU EXP 1216S), which contain microbes as the active ingredient, were evaluated on summer squash and cantaloupe against powdery mildew when applied alone or in alternation with a half-rate of conventional fungicide under greenhouse and field conditions. In greenhouse experiments, the product BU EXP $1216 \mathrm{~S}$ significantly $(P<0.05)$ reduced the disease severity by nearly $70 \%$ relative to the water control. The level of control achieved was not significantly different from that obtained with Procure 480SC (triflumizole), the half-rate of conventional fungicide treatment, in two of four greenhouse experiments. Compared with the untreated water control, BU EXP 1216C and BU EXP 1216S, when applied alternately with Procure 480SC, consistently promoted plant growth measured by plant height, stem caliper, total fresh weight, and chlorophyll content in the leaves. The degree of increase was 11.6 and $11.3 \%$ in plant height, 15.6 and $19.8 \%$ in stem caliper, 25 and $40.7 \%$ in chlorophyll content, and 164 and $250 \%$ in total fresh weight, respectively. Alternating applications of these products with Procure 480SC resulted in sig-

nificantly less powdery mildew disease than in the water control. In the first field trial on summer squash, all products applied individually or in alternation with Procure 480SC significantly reduced the severity of powdery mildew at the early stage (60 days after planting [DAP]) of disease development. Moreover, these alternating treatments resulted in significantly better control than with Procure 480SC alone at the late assessment stage (88 DAP). The products in alternation with Procure 480SC had a level of disease reduction equivalent to Procure 480SC alone on cantaloupe and significantly reduced disease severity in comparison with the water control. Compared with applying the microbial products alone, alternating applications of these products with Procure 480SC significantly reduced disease severity on cantaloupe and improved the marketable fruit number and weight. The data from our studies suggest that these microbial products could be effectively incorporated into disease management programs. In particular, these microbial products could be integrated into the management of powdery mildew on summer squash and cantaloupe in Florida by alternating their application with low rates of conventional fungicides, potentially reducing the development of fungicide resistance in the pathogen population.
\end{abstract}

Powdery mildew, caused by Podosphaera xanthii (syn. Sphaerotheca fuliginea auct. p.p. (Schltdl.) Pollacci), is a common and severe disease of cucurbits in most areas of the world $(17,18)$. Powdery mildew can cause substantial reductions in plant growth, premature defoliation, and, consequently, significant reductions in yields of cucurbits $(11,17)$. In Florida, powdery mildew is a major disease problem in squash and cantaloupe production and occurs under both greenhouse and field conditions. Recently, the disease has occurred every year and the infection is present in approximately $70 \%$ of the squash acreage in Florida (18).

Application of fungicides is the primary practice for management of powdery mildew of cucurbits $(12,17)$. Control of powdery mildew with conventional chemicals is achieved by repeated foliar applications of systemic fungicides. However, frequent applications of chemical fungicides may cause potential impacts on the environment, and often result in the selection of pathogen strains

\section{Corresponding author: S. Zhang, E-mail: szhang0007@ufl.edu}

Trade names in this publication are used solely for the purpose of providing specific information. Such use herein is not a guarantee or warranty of the products named and does not signify that they are approved to the exclusion of others. Mention of a proprietary product does not constitute an endorsement by the University of Florida nor does it imply lack of efficacy of similar products not mentioned.

Accepted for publication 16 December 2010.

doi:10.1094/PDIS-07-10-0521

(C) 2011 The American Phytopathological Society that are resistant or tolerant to the fungicide applied. For instance, resistance to the fungicides triadimefon and benomyl has been reported in pathogen strains throughout the United States $(11,16)$. To achieve effective ongoing control of powdery mildew, the use of fungicides must be carefully managed. Thus, the development of environmentally friendly nonchemical alternatives is desirable and would be helpful for control of $P$. xanthii. This is especially important for growers operating low-input or organic production farms and those who plant cucurbits in backyards and community gardens where the use of chemicals is restricted.

There is a large body of literature regarding the biological control of powdery mildew on various crops. A commercial product, AQ10, containing the fungus Ampelomyces quisqualis Ces., was developed specifically for control of powdery mildew. It has been reported that A. quisqualis parasitizes and destroys powdery mildew fungi (15). A yeast-like fungus, Sporothrix flocculosa (syn. Pseudozyma flocculosa), has been tested for controlling powdery mildew of cucumber and was used with promising results under greenhouse conditions (6). Sporodex, a wettable powder of this fungus, has been formulated to control powdery mildew on greenhouse crops (21).

However, biological fungicides are generally not as effective as the conventional synthetic fungicides at controlling powdery mildew. To improve the control of powdery mildew in cucurbits, biofungicides might be applied in combination or in alternation with effective conventional fungicides. Based on the results in field trials, McGrath and Shishkoff (15) indicated that excellent control of powdery mildew may be achieved by the use of combinations of a biofungicide with a conventional systemic fungicide at an early stage of disease development. Bay et al. (1) evaluated Actinovate 
AG (a preparation of Streptomyces lydicus WYEC 108) for powdery mildew on pumpkin, and found that alternating its use with the chemical fungicide Quintec (quinoxyfen) reduced upper leaf severity about 50-fold compared with the water control. Actinovate AG is a biological fungicide used for control of root and foliar pathogens on many crops. When applied as a foliar spray, it effectively suppresses many foliar diseases, including powdery mildew. Companion is a biological fungicide containing the naturally occurring beneficial bacterium Bacillus subtilis GB03, which suppresses a broad spectrum of foliar and root diseases. B. subtilis GB03 combats crop pathogens through multiple modes of action. It quickly colonizes root surfaces and outgrows pathogens in the soil, produces antibiotics that disrupt the cell wall formation of pathogens, and stimulates the plants' own natural immune system (induced systemic resistance). BU EXP 1216 (C and S formulations) contains $B$. subtilis strain MBI 600 , which is used to suppress a variety of plant pathogens on many crops and to promote plant growth for improved yields.

The overall goal of this research was to evaluate the potential of microbial products individually or in succession with the conventional fungicide Procure 480SC at reduced rates or extended spray intervals for powdery mildew disease control. The rationale for the reduced rates and lengthened spray interval was to reduce the number of chemical applications while retaining a significant level of disease control by alternating conventional fungicides with biofungicides, which would benefit the growers who do not want to rely on application of conventional fungicides for this disease control. The specific objectives of this study were to (i) evaluate the effects of these microbial products on powdery mildew disease of summer squash and cantaloupe under greenhouse and field conditions in Florida and (ii) determine whether alternating application of these biological products, each with reduced rates of a systemic fungicide, Procure 480SC, could improve powdery mildew control obtained with the biologicals when applied alone.

\section{Materials and Methods}

Microbial products and conventional systemic fungicide. Four microbial products were tested in this study (Table 1). The products evaluated in this study (and relevant information) were Actinovate AG, which contains $0.0371 \%$ of S. lydicus WYEC 108 $\left(1 \times 10^{7} \mathrm{CFU} \mathrm{g}^{-1}\right.$; Natural Industries, Inc., Houston); Companion, which contains $0.03 \%$ B. subtilis GB03 $\left(1.5 \times 10^{7} \mathrm{CFU} \mathrm{m}{ }^{-1}\right.$; Growth Products, Ltd., White Plains, NY); and BU EXP 1216C and BU EXP 1216S, which contain the same active ingredient (i.e., $2.75 \%$ B. subtilis MBI600, $5.5 \times 10^{10} \mathrm{CFU} \mathrm{g}^{-1}$ ) but which differ in the diluents used to normalize spore counts and act as the carrier for the products (Becker Underwood, Ames, IA). BU EXP 1216S has a water-soluble diluent whereas BU EXP 1216C has a waterinsoluble diluent. Procure 480SC (Chemtura Corporation, Middle- bury, CT), a systemic fungicide registered on cucurbits for powdery mildew control, was included in all experiments as a conventional fungicide.

Greenhouse experiment. Plant material. Squash seed were planted to a depth of approximately 1 to $2 \mathrm{~cm}$ in 10 -cm-diameter plastic pots containing soilless Pro-mix growing medium (MiracleGro Lawn Products, Inc., Marysville, $\mathrm{OH}$ ) and watered daily in a greenhouse at the Tropical Research and Education Center (TREC), University of Florida, Homestead. A controlled-release fertilizer, Osmocote PLUS (15-9-12; Scotts-Sierra Horticultural Products Company, Marysville, $\mathrm{OH}$ ), was mixed into the soilless potting Pro-mix medium at a rate of $1.3 \%(\mathrm{wt} / \mathrm{wt})$ prior to seed planting.

Treatment with microbial products. In total, 10 treatments were included in the greenhouse experiment. The treatments included four individual microbial products, a conventional fungicide treatment with Procure 480SC, each microbial product applied in alternation with Procure 480SC, and a water treatment as the nontreated control (Table 1). Beginning at 1 week after planting (WAP), treatments were applied once a week for microbial products alone and once every 2 weeks for each of the microbial products and Procure 480SC in alternating treatments, and for Procure 480SC alone. The application rate was $2.25 \mathrm{~g} \mathrm{liter}^{-1}$ for Actinovate AG, $6.26 \mathrm{ml} \mathrm{liter}^{-1}$ for Companion, and $9.0 \mathrm{~g} \mathrm{liter}^{-1}$ for both BU EXP 1216C and BU EXP 1216S. Procure 480SC was applied at $1.56 \mathrm{ml} \mathrm{liter}^{-1}$, equivalent to a high rate of $584 \mathrm{ml} \mathrm{ha}^{-1}$ in greenhouse trials 1 and 2. To evaluate whether alternating application of Procure 480SC applied at low rates could provide a level of powdery mildew control equivalent to its effect at high rates, Procure 480SC was applied in the alternating treatments at a low rate (i.e., $292 \mathrm{ml} \mathrm{ha}^{-1}$ in trials 3 and 4). Squash plants were treated by spraying solutions of treatments onto the whole plant until runoff using a 200-ml handheld sprayer. In total, five applications, consisting of three applications of microbial products and two of Procure 480SC, were made for all trials in the greenhouse experiment.

Inoculation with Podosphaera xanthii and disease rating. Four separately repeated trials were conducted in temperature-controlled greenhouses at TREC of University of Florida in Homestead. Following the first treatment with microbial products (or Procure 480SC) at 1 WAP, squash plants were placed along with 20 squash plants with symptoms of powdery mildew as a source of infection onto benches in the greenhouse. The powdery mildew-infected plants had been maintained in a greenhouse for 3 to 4 WAP when the experimental plants were moved into the greenhouse. Powdery mildew colonies covered 40 to $50 \%$ of the surfaces of the fully developed squash leaves except for two or three young terminal leaves of each plant. Powdery mildew disease was visually rated on each entire test plant as the percentage of the leaf surface covered with powdery mildew colonies on fully developed leaves at 6 WAP

Table 1. Effects of microbial products applied alone or in alternation with Procure 480SC on powdery mildew of summer squash under greenhouse conditions at Homestead ${ }^{\mathrm{x}}$

\begin{tabular}{lcccc}
\hline & \multicolumn{4}{c}{ Powdery mildew severity (\%) $^{\mathbf{y}}$} \\
\cline { 2 - 5 } Treatment $^{\mathbf{z}}$ & Trial 1 & Trial 2 & Trial 3 & Trial 4 \\
\hline Actinovate & $73.1 \mathrm{a}$ & $67.9 \mathrm{a}$ & $59.4 \mathrm{c}$ & $87.1 \mathrm{a}$ \\
Companion & $77.9 \mathrm{a}$ & $81.3 \mathrm{a}$ & $68.8 \mathrm{bc}$ & $80.9 \mathrm{ab}$ \\
BU EXP 1216 C & $98.8 \mathrm{a}$ & $76.4 \mathrm{a}$ & $84.4 \mathrm{a}$ & $75.1 \mathrm{ab}$ \\
BU EXP 1216 S & $28.0 \mathrm{bc}$ & $37.1 \mathrm{~b}$ & $36.9 \mathrm{~d}$ & $58.5 \mathrm{~b}$ \\
Actinovate alt. Procure 480SC & $9.8 \mathrm{c}$ & $18.1 \mathrm{bc}$ & $10.8 \mathrm{f}$ & $21.3 \mathrm{c}$ \\
Companion alt. Procure 480SC & $9.3 \mathrm{c}$ & $5.4 \mathrm{c}$ & $16.4 \mathrm{ef}$ & $17.5 \mathrm{c}$ \\
BU EXP 1216 C alt. Procure 480SC & $8.3 \mathrm{c}$ & $18.8 \mathrm{bc}$ & $28.1 \mathrm{de}$ & $19.4 \mathrm{c}$ \\
BU EXP 1216 S alt. Procure 480SC & $8.4 \mathrm{c}$ & $6.3 \mathrm{c}$ & $12.0 \mathrm{f}$ & $11.3 \mathrm{c}$ \\
Procure 480SC & $38.8 \mathrm{~b}$ & $23.8 \mathrm{bc}$ & $5.5 \mathrm{f}$ & $10.1 \mathrm{c}$ \\
Water CK & $88.1 \mathrm{a}$ & $87.0 \mathrm{a}$ & $82.5 \mathrm{ab}$ & $94.4 \mathrm{a}$ \\
\hline
\end{tabular}

${ }^{\mathrm{x}}$ Data are means of eight replications with one plant in each replication. Means within a column followed by the same letter are not significantly different $(P$ $=0.05$ ) according to the least significant difference test.

${ }^{y}$ Powdery mildew disease was visually rated as the percentage of the surface of fully developed leaves covered with powdery mildew lesions.

${ }^{\mathrm{z}}$ Summer squash 'Goldbar' was used in greenhouse trials 1 and 2, and Procure 480SC was applied at full label rate (or high label rate) of $584 \mathrm{ml}^{-1}$. 'Medallion' squash was planted in trials 3 and 4, and Procure 480SC was applied at a low rate of $292 \mathrm{ml} \mathrm{ha}^{-1}$. Applications were made once every week, except the Procure 480SC-alone treatment and alternating treatments in which either microbial products or Procure 480SC were applied every 2 weeks. 
for the greenhouse experiment. The youngest leaves, which were symptom free, were excluded in the disease rating. 'Goldbar' squash was planted in trials 1 and 2 and 'Medallion' was used in trials 3 and 4 . Each treatment consisted of eight replications, with one plant in each replicate. The experiment was arranged in a randomized complete block design. Disease data collected from the greenhouse were subjected to analysis of variance (ANOVA). Treatment means were separated by Fisher's protected least significant difference (LSD) test at $P=0.05$. All analyses were conducted with JMP software (JMP 5.0; SAS Institute Inc., Cary, NC).

Effect of microbial products on the growth of squash. In the greenhouse experiment as described above, plant height was measured from the soil surface to the base of the blade of the top-most leaf 4 WAP in trials 1 and 2. The caliper (diameter) of the plant stem was also measured for each plant above the first node where the cotyledons emerged from the stem using a certified digital caliper (Fisher Scientific). Chlorophyll content in leaves was determined using a Minolta Chlorophyll Meter (model SPAD-502; Spectrum Technologies, Inc., Plainfield, IL). Three measurements of chlorophyll content were made on the second fully developed leaf from the top of each plant, and the average value was used for data analysis. Total fresh weight of squash plants was determined at 6 WAP following disease rating by rinsing the loose soil off the roots, blotting away excess water, and weighing the entire plant on an electronic scale. Data of plant growth parameters (i.e., plant height, stem caliper, chlorophyll content in squash leaves, and total fresh plant weight) were subjected to ANOVA and analyses were conducted with JMP software (JMP 5.0; SAS Institute Inc.). The Fisher's protected LSD test at $P=0.05$ was used to separate the means of treatments.

Field experiments. To evaluate the efficacy of the microbial products against powdery mildew on cucurbits, two field trials on summer squash at TREC in Homestead and another two on cantaloupe were conducted at the Gulf Coast Research and Education Center (GREC) in Balm, FL during 2009 to 2010. Beginning at 2 to $3 \mathrm{WAP}$, treatments were applied once a week for microbial products alone and once every 2 weeks for each of the microbial products and Procure 480SC in alternating treatments, and for Procure 480SC alone. Procure 480SC was used at the high rate except for Homestead trial 2, where it was applied at the reduced rate. The application rate was the same as that in greenhouse experiments (i.e., $2.25 \mathrm{~g} \mathrm{liter}^{-1}$ for Actinovate AG, $6.26 \mathrm{ml} \mathrm{liter}^{-1}$ for Companion, and 9.0 $\mathrm{g} \mathrm{liter}^{-1}$ for both BU EXP 1216C and BU EXP 1216S). All field practices, including land preparation, fertility, irrigation, weed control, and pest management, followed the guidelines of the University of Florida/IFAS (20).

Field trials on summer squash in Homestead. In field trial 1, summer squash HMX 5703 F1 hybrid (Harris Moran Seed Company, Modesto, CA) was direct seeded into fumigated beds covered with metalized plastic mulch on 23 November 2009. In field trial 2, seed of 'Medallion' squash (Abbott \& Cobb. Inc., Feasterville, PA) were planted on 1 March 2010. Seed were sown into the soil of raised beds previously fumigated with methyl bromide (MC33) at $393 \mathrm{~kg} \mathrm{ha}^{-1}$ and covered with metalized polyethylene mulch. The beds were $15 \mathrm{~cm}$ high by $76 \mathrm{~cm}$ wide, with $274 \mathrm{~cm}$ between bed centers. Three seeds of squash were sown at each site with $51 \mathrm{~cm}$ between adjacent plants on the bed. The seedlings were thinned to one plant per site 2 WAP. The same 10 treatments from the greenhouse experiment were included in the field trials and arranged in a randomized complete block design. Each plot consisted of one bed and was $6 \mathrm{~m}$ long, with $1.5-\mathrm{m}$ buffer zones maintained between plots.

In both field trials at TREC, squash plants were infected with naturally occurring powdery mildew pathogen, Podosphaera xanthii, and symptoms of powdery mildew primarily occurred on the underside of leaves at the time of disease ratings. In trial 1 , foliar treatments were applied with a $\mathrm{CO}_{2}$ backpack sprayer calibrated to deliver 374 liters $\mathrm{ha}^{-1}$ starting at 17 days after planting (DAP), when no symptoms of powdery mildew were found on squash plants in the control plots, and continued at $24,31,45,52,59,66$, and 73 DAP. Procure 480SC was applied at the high rate of $584 \mathrm{ml}$ $\mathrm{ha}^{-1}$. Treatments were applied once a week for microbial products alone, once every 2 weeks for the microbial products and Procure 480SC for alternating treatments, and every 2 weeks for Procure 480SC alone. Plots were monitored regularly for occurrence of powdery mildew and the disease was rated at $60,74,80$, and 88 DAP. Disease severity of powdery mildew was evaluated on five randomly selected plants in each plot by visual assessments on the entire canopy using a rating scale of 0 to 5 , where $0=$ no symptoms and $5=$ the highest level of powdery mildew disease (19).

In trial 2, the rate of Procure 480SC was applied at a low rate (i.e., $\left.292 \mathrm{ml} \mathrm{ha}^{-1}\right)$ in contrast to the high rate $\left(584 \mathrm{ml} \mathrm{ha}^{-1}\right)$ applied in field trial 1. In addition, a treatment with Procure 480SC alone at a high rate of $584 \mathrm{ml} \mathrm{ha}^{-1}$ was included as the conventional fungicide control. Foliar treatments were applied with a $\mathrm{CO}_{2}$ backpack sprayer calibrated to deliver 374 liters $\mathrm{ha}^{-1}$ starting at 24 DAP, when half of the old leaves were infected in the control plots and an average of three colonies was found on each leaf. Subsequent treatments were made at 31, 38, 44, 51, and 59 DAP. Disease severity of powdery mildew was visually rated on the entire canopy at 59, 71, and 77 DAP, and recorded as the percentage of the leaf surface covered with powdery mildew on fully developed leaves (15). Area under the disease progress curve (AUDPC) was calculated throughout the period of experiment in both field trials. Marketable fruit were harvested three times in trial 1 and two times in trial 2, and total yields were recorded for data analysis. Data of AUDPC and yield from each plot were subjected to ANOVA. Means of treatments were separated by Fisher's protected LSD test at $P=0.05$. All analyses were conducted with JMP software (JMP 5.0; SAS Institute Inc.).

Field trials on cantaloupe in Balm. In 2009 and 2010, field trials were conducted at GREC, University of Florida, Balm, to assess these microbial products for their potential to manage powdery mildew on cantaloupe. Plots consisted of 2.4-m-long bed sections within 91.2-m-long raised beds with 1.2-m center-to-center bed spacing. Beds were fumigated with methyl bromide (MC33) at 393 $\mathrm{kg} \mathrm{ha}^{-1}$ and covered with black virtually impermeable mulch (Orgalloy; Atofina Chemical Inc., Philadelphia) and irrigated with a drip-tape system. In trial 1 in 2009, seed of the cantaloupe ('Hale's Best') were planted at 91.2-cm spacing along beds, skipping a 1.8$\mathrm{m}$ alley between plots and every third bed as a buffer. Treatments were applied at 34, 41, 48, 55, 62, 69, and 88 DAP with a $\mathrm{CO}_{2}$ backpack sprayer calibrated to deliver 374 to 935 liters ha $^{-1}$ at 2.81 $\mathrm{kg} \mathrm{cm}^{-2}$. Treatments, including a nontreated control, were arranged in a randomized complete block design with each treatment repeated four times. Plots were monitored regularly for powdery mildew and rated at 68 and 83 DAP after disease reached appreciable levels across the trial. Marketable yields were assessed from two separate hand harvests of plots at 83 and 89 DAP. In trial 2, the field operation and experimental design as described above were conducted in 2010. However, treatments were applied at 50, 62, 68, and 76 DAP, and disease severity was rated at 65 and 79 DAP. No marketable yield data were collected for this trial. The severity of powdery mildew was assessed as the percentage of canopy affected. The Horsfall-Barratt scale was used for all ratings but values were converted to mid-percentages prior to statistical analyses. Data of AUDPC and yield from each plot were subjected to ANOVA. Means of treatments were separated by Fisher's protected LSD test at $P=0.05$. Analyses were conducted with SAS software (SAS 8.2; SAS Institute Inc.).

\section{Results}

Efficacy of microbial products applied individually or in alternation with Procure 480SC against powdery mildew on summer squash under greenhouse conditions. In all greenhouse trials, the B. subtilis MBI600 product, BU EXP 1216S, alone significantly $(P<0.05)$ reduced disease severity of powdery mildew compared with the water control (Table 1). The efficacy (relative severity of disease) of BU EXP $1216 \mathrm{~S}$ ranged from 38 to $68 \%$ relative to the water control. The effect of BU EXP 1216S on pow- 
dery mildew suppression in the greenhouse experiment was as effective in two of four greenhouse trials as the conventional fungicide Procure 480SC (triflumizole) applied every other week for powdery mildew control on cucurbits. When applied in alternation with Procure 480SC, all microbial products significantly suppressed disease of powdery mildew in four repeated greenhouse trials when compared with the water control. More interestingly, alternating the applications of the microbial products Actinovate AG (S. lydicus), Companion (B. subtilis GB03), and BU EXP 1216C (B. subtilis MBI600) each with Procure 480SC resulted in significantly lower powdery mildew disease compared with each individual product alone and with Procure 480SC alone in trial 1. In trials 2,3 , and 4 , the effects of microbial products applied in alternation with Procure 480SC on powdery mildew disease reduction were significantly greater than the effects of each microbial product alone but not greater than that of Procure 480SC alone.

Effect of microbial products on growth of summer squash in the greenhouse. Actinovate AG and Companion each significantly increased stem caliper when compared with the water control (Fig. 1B). BU EXP 1216C demonstrated significant effects on increases in stem caliper, chlorophyll content in leaves as measured by SPAD reading (Fig. 1C), and total fresh weight of each plant (Fig. 1D) compared with the water control. BU EXP 1216S resulted in a significant increase in chlorophyll content in leaves and total fresh weight of each plant compared with the water control. When applied in alternation with Procure 480SC, BU EXP 1216C and BU EXP 1216S significantly increased all four parameters. The effect of BU EXP 1216S in alternation with Procure 480SC resulted in greater plant total fresh weight than either BU EXP 1216S or Procure 480SC alone. Alternating applications of Actinovate AG with Procure 480SC resulted in significant increases in all parameters except stem caliper.

Efficacy of microbial products against powdery mildew on summer squash and cantaloupe under field conditions. Field trials on squash in Homestead. In field trial 1, based on the
AUDPC values across four disease ratings, microbial products Actinovate AG and BU EXP 1216 S both significantly $(P<0.0001)$ reduced powdery mildew disease development compared with the water control (Table 2). Treatments with all microbial products, each applied in alternation with Procure 480SC at $584 \mathrm{ml} \mathrm{ha}^{-1}$, resulted in significantly lower AUDPC values than the water control. In the first rating at 60 DAP, squash plants treated with all microbial products individually had significantly lower disease compared with the water control, with the least disease in treatment with Procure 480SC (Fig. 2). In the second rating at 74 DAP, only BU EXP 1216 S alone significantly reduced powdery mildew disease severity compared with the water control. In the third and fourth ratings, at 80 and $88 \mathrm{DAP}$, respectively, no microbial product alone significantly reduced powdery disease. In all disease ratings, alternating applications of each microbial product with Procure 480SC resulted in significantly lower disease compared with each product alone (Fig. 2). The effect of alternating applications of the microbial products with Procure 480SC at the fourth rating was greater than that of Procure 480SC alone but it was not as effective as Procure 480SC at the first rating. In the second and third ratings, alternating applications resulted in levels of disease reduction equivalent to Procure 480SC. Interestingly, the effect of all four microbial products, each applied in alternation with Procure 480SC, was significantly greater than that of the microbial product alone or Procure 480SC by itself in the fourth rating at 88 DAP. In addition, alternating applications of Actinovate AG, Companion, and BU EXP 1216C each with Procure 480SC significantly increased the yields of squash, so much so that the respective resulting yields were approximately double those of the water control (Table 2).

In field trial 2 , only Companion alone significantly $(P<0.05)$ reduced disease development of powdery mildew on squash compared with the water control (Table 2). Microbial products Actinovate AG, Companion, and BUEXP $1216 \mathrm{C}$, each applied in alternation with Procure 480SC at $292 \mathrm{ml} \mathrm{ha}^{-1}$, had a significant
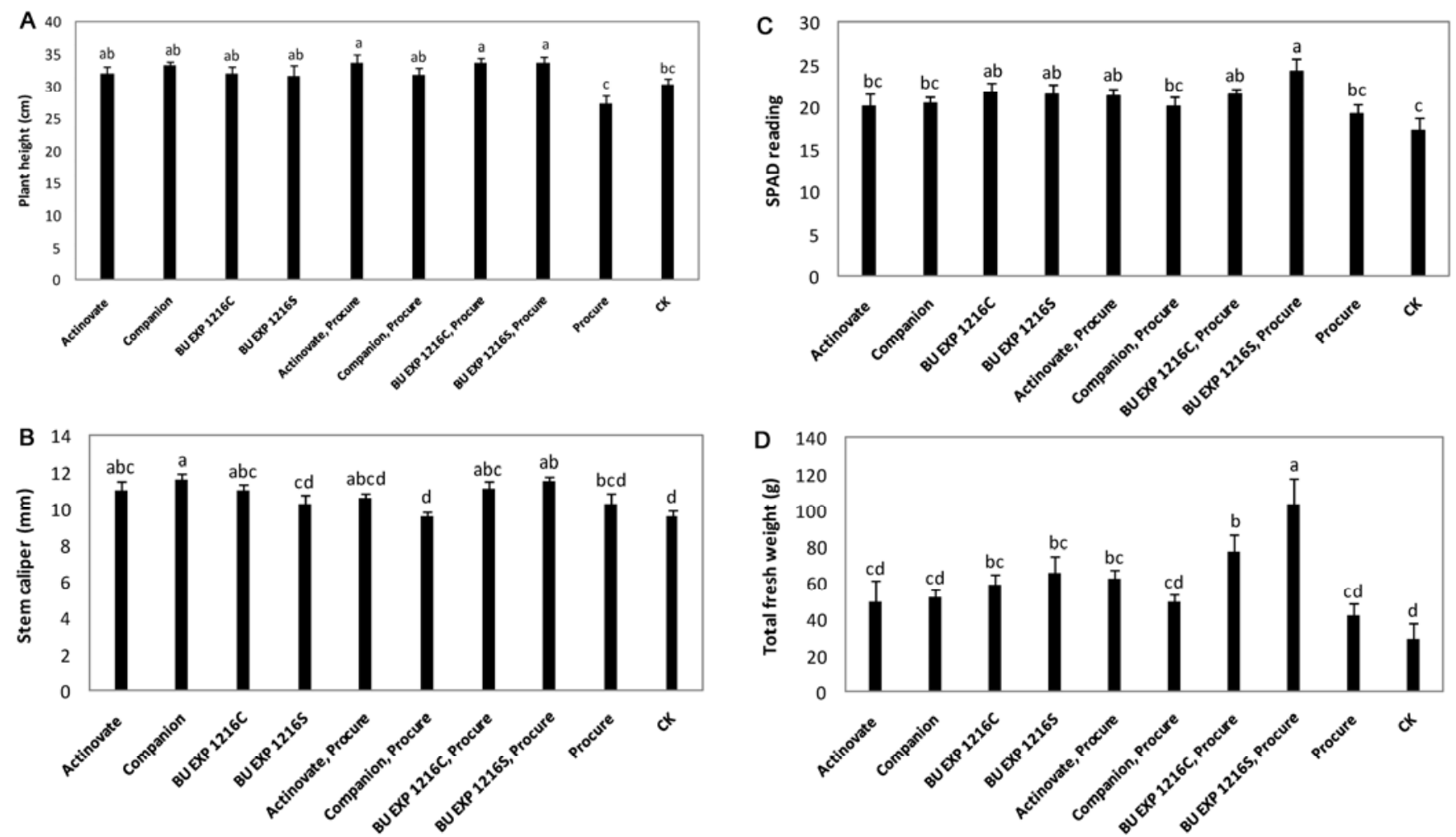

Fig. 1. Effect of microbial products applied individually or in alternation with Procure 480SC on plant growth of summer squash 'Goldbar' under greenhouse conditions. Data are means from two repeated greenhouse trials 1 and 2 . A, Plant height; $\mathbf{B}$, stem caliper; $\mathbf{C}$, chlorophyll contents in leaves; and $\mathbf{D}$, total fresh plant weight. Bars represent the standard error of the mean. The application rate was $2.25 \mathrm{~g} \mathrm{liter}^{-1}$ for Actinovate AG, $6.26 \mathrm{ml}_{\text {liter }}^{-1}$ for Companion, and $9.0 \mathrm{~g}$ liter ${ }^{-1}$ for both BU EXP $1216 \mathrm{C}$ and BU EXP 1216S. Procure 480SC was applied at $1.56 \mathrm{ml} \mathrm{liter}^{-1}$, equivalent to a high rate of $584 \mathrm{ml} \mathrm{ha}^{-1}$. Applications were made once every week, except the Procure $480 \mathrm{SC}$-alone treatment and alternating treatments in which either microbial products or Procure 480SC were applied every 2 weeks. 
effect on reduction in disease development of powdery mildew. Efficacy of Procure 480SC against powdery mildew was similar when applied at $584 \mathrm{ml} \mathrm{ha}^{-1}$ as at $292 \mathrm{ml} \mathrm{ha}^{-1}$. At the first rating (59 DAP), alternating applications of all microbial products, each with Procure $480 \mathrm{SC}$ at $292 \mathrm{ml} \mathrm{ha}^{-1}$, significantly reduced powdery mildew disease when compared with the water control (Fig. 3). At the second (71 DAP) and third ratings (77 DAP), the effect of microbial products on disease reduction diminished in most treatments regardless of being applied alone or in alternation with Procure 480SC. At the second rating, Companion was the only microbial product that demonstrated a significant effect on disease reduction both when applied alone or in alternation with Procure 480SC. At the third rating, both Actinovate AG and BU EXP $1216 \mathrm{C}$, when each was alternated with Procure 480SC, significantly reduced disease severity of powdery mildew compared with the water control. When applied at the high or low label rate, Procure 480SC had similar effects on disease reduction when applied at the 14-day interval. In addition, only Actinovate AG, when applied in alternation with Procure 480SC, significantly increased yields of squash compared with the water control (Table 2).

Table 2. Effects of microbial products applied individually or in alternation with Procure 480SC on powdery mildew severity and yield in summer squash HMX 5703 F1 hybrid (trial 1) and 'Medallion' squash (trial 2) in Homestead in 2009 to $2010^{y}$

\begin{tabular}{|c|c|c|c|c|}
\hline \multirow[b]{2}{*}{ Treatment $^{\mathrm{z}}$} & \multicolumn{2}{|c|}{ Trial 1} & \multicolumn{2}{|c|}{ Trial 2} \\
\hline & AUDPC & Yield (kg/plot) & AUDPC & Yield (kg/plot) \\
\hline Actinovate AG & $106 \mathrm{bc}$ & $4.0 \mathrm{ab}$ & $1,348 \mathrm{a}$ & $9.6 \mathrm{abc}$ \\
\hline Companion & $112 a b c$ & $3.7 \mathrm{ab}$ & $1,203 \mathrm{bcd}$ & $7.0 \mathrm{c}$ \\
\hline BU EXP 1216 C & $119 \mathrm{ab}$ & $4.7 \mathrm{ab}$ & $1,332 \mathrm{a}$ & $10.2 \mathrm{ab}$ \\
\hline BU EXP $1216 \mathrm{~S}$ & $99 \mathrm{c}$ & $3.3 \mathrm{~b}$ & $1,257 \mathrm{ab}$ & $10.1 \mathrm{ab}$ \\
\hline Actinovate AG alt. Procure 480SC & $48 \mathrm{~d}$ & $6.2 \mathrm{a}$ & $1,129 \mathrm{~cd}$ & $11.9 \mathrm{a}$ \\
\hline Companion alt. Procure 480SC & $51 \mathrm{~d}$ & $6.1 \mathrm{a}$ & $1,154 \mathrm{bcd}$ & $9.7 \mathrm{abc}$ \\
\hline BU EXP $1216 \mathrm{C}$ alt. Procure 480SC & $54 \mathrm{~d}$ & $6.7 \mathrm{a}$ & $1,207 \mathrm{bcd}$ & $9.9 \mathrm{ab}$ \\
\hline BU EXP 1216 S alt. Procure 480SC & $46 \mathrm{~d}$ & $4.8 \mathrm{ab}$ & $1,239 \mathrm{abc}$ & $10.2 \mathrm{ab}$ \\
\hline Procure 480SC & $47 \mathrm{~d}$ & $5.9 \mathrm{ab}$ & $1,085 \mathrm{de}$ & $11.4 \mathrm{ab}$ \\
\hline $1 / 2$ Procure $480 \mathrm{SC}$ & $\mathrm{n} / \mathrm{a}$ & $\mathrm{n} / \mathrm{a}$ & $1,068 \mathrm{de}$ & $10.9 \mathrm{ab}$ \\
\hline Water CK & $124 \mathrm{a}$ & $3.2 \mathrm{~b}$ & $1,361 \mathrm{a}$ & $11.1 \mathrm{ab}$ \\
\hline
\end{tabular}

y Disease severity was evaluated on five randomly selected plants per plot at 60,74, 80, and 88 days after planting (DAP) in trial 1 and at 59, 71, and 77 DAP in trial 2 by visual assessments on the entire canopy using a rating scale of 0 to 5 , where $0=$ no symptoms and $5=$ the highest level of powdery mildew disease. Area under the disease progress curve (AUDPC) values were calculated throughout the period of the trial. Means within a column followed by the same letter are not significantly different $(P=0.05)$ according to the least significant difference test; $\mathrm{n} / \mathrm{a}=$ not available.

${ }^{\mathrm{z}}$ Procure 480SC was applied at the high label rate of $584 \mathrm{ml} \mathrm{ha}^{-1}$ in field trial 1, whereas it was sprayed at the low label rate of $292 \mathrm{ml} \mathrm{ha}^{-1}$ in trial 2. Applications were made once every week, except the Procure 480SC-alone treatment and alternating treatments in which either microbial products or Procure $480 \mathrm{SC}$ were applied every 2 weeks. Alternating treatments were made at 17, 24, 31, 45, 52, 59, 66, and 73 DAP in trial 1 and at 24, 31, 38, 44, 51, and 59 DAP in trial 2.

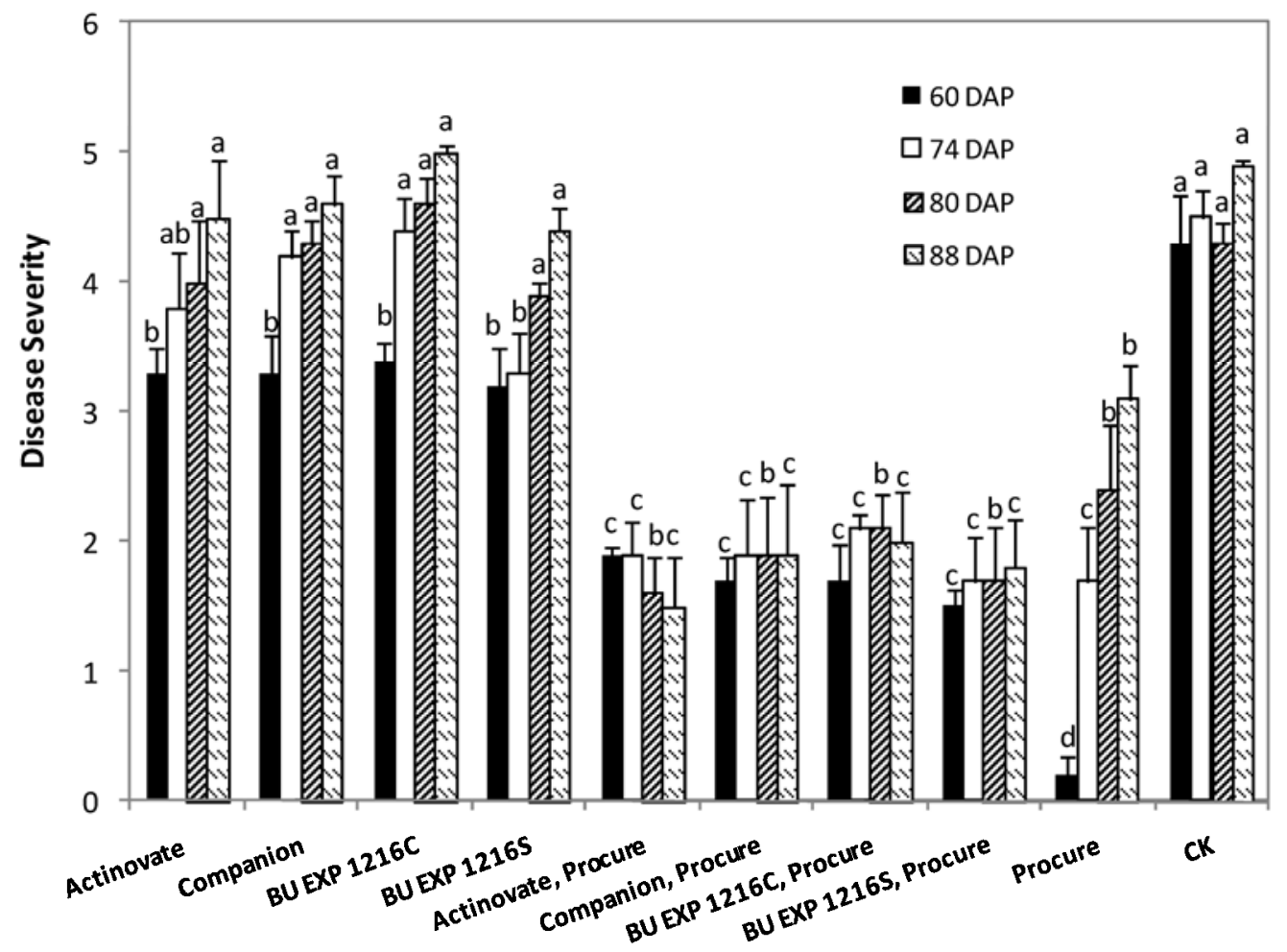

Fig. 2. Efficacy of microbial products applied alone or in alternation with Procure 480SC on powdery mildew of summer squash HMX $5703 \mathrm{~F} 1$ hybrid in field trial 1 in Homestead, 2009 to 2010. The application rate was $2.25 \mathrm{~g} \mathrm{liter}^{-1}$ for Actinovate AG, $6.26 \mathrm{ml}^{\text {liter }}{ }^{-1}$ for Companion, and $9.0 \mathrm{~g} \mathrm{liter}^{-1}$ for both BU EXP $1216 \mathrm{C}$ and BU EXP 1216S. Procure 480SC was applied as a high rate of $584 \mathrm{ml} \mathrm{ha}^{-1}$. Treatments were applied once a week for microbial products alone, and once every 2 weeks for each of the microbial products and Procure 480SC in alternating treatments, and for Procure 480SC alone. Disease severity was evaluated on five randomly selected plants per plot at $60,74,80$, and 88 days after planting by visual assessments on the entire canopy using a rating scale of 0 to 5 , where $0=$ no symptoms and $5=$ the highest level of powdery mildew disease. Means on each rating date followed by the same letter are not significantly different $(P=0.05)$ according to the least significant difference test. Bars represent the standard error of the mean. 
Field trials on cantaloupe in Balm. In trial 1, based on disease severity rated at 83 DAP, the effectiveness of all biological products was improved by alternating with Procure 480SC (Table 3). More importantly, alternating applications of Companion with Procure 480SC significantly improved the activity of Procure 480SC alone. AUDPC values between the products alternating with Procure 480SC and Procure 480SC alone were not significantly different. However, the effectiveness of the products in reducing disease progress was significantly ameliorated when alternated with Procure 480SC compared with applying the biological products alone $(P=0.0023)$. No significant difference in the average size of fruit was shown between treatments $(P=0.712)$. Compared with the water control, the application of the products alone did not significantly increase the total marketable fruit number and weight. In contrast, the biological products alternating with Procure 480SC significantly increased the fruit number and weight $(P$ $=0.0272$ and 0.0066 , respectively). No significant difference in marketable fruit yields was observed between Procure 480SC alone and applied in sequence with the biological products.

In trial 2, based on AUDPC and disease severity at 79 DAP, the bioproducts alternating with Procure 480SC significantly improved the effectiveness of disease reduction compared with applying bioproducts alone ( $P=0.016$ and 0.011 , respectively). Although disease severity and AUDPC between the products, Procure 480SC, and the water control were not significant, alternating applications of the bioproducts with Procure 480SC significantly reduced disease development compared with the water control (Table 4). When alternated with the bioproducts, applying Procure 480SC resulted in numerically lower disease severity and AUDPC than Procure 480SC itself.

\section{Discussion}

Some of the microbial products evaluated in this study significantly reduced powdery mildew disease of summer squash and cantaloupe under greenhouse and field conditions when applied individually or in alternation with a conventional chemical fungicide when compared with the water control. Stem caliper of squash plants was increased with the application of Actinovate, Companion, and BUEXP 1216C when compared with the water control. Chlorophyll content in squash leaves was increased with both of the BUEXP1216 formulations. Total fresh weight of summer squash plants in greenhouse assays was increased with the use of these materials as well. Treatments with some of the microbial products in alternation with Procure 480SC resulted in significantly greater yields compared with the water control under field conditions in Florida, although there was inconsistency between years and locations.

Many studies have been conducted using biofungicides to suppress powdery mildew on several crops. Actinovate AG, Companion, and MBI 600 (a strain of B. subtilis, the active ingredient in BU EXP 1216C and BU EXP 1216S) have been evaluated by many research groups demonstrating variation in control efficacy against powdery mildew on cucurbits, grape, strawberry, and tomato. McGrath and Fox (14) reported that both Actinovate AG and Companion significantly protected tomato from powdery mildew in field trials. It has also been reported that Actinovate AG was effective in suppressing powdery mildew on grape (4) and strawberry (22). Treatment with MBI 600 resulted in significantly lower severity $(4.3 \%)$ of powdery mildew on grapevine compared with the untreated control (79\%) (3). However, a similar result was not obtained on grape with Actinovate AG by Janousek et al. (5). In our study, Actinovate AG alone did not reduce powdery mildew disease compared with the control treatment, with the exception of the first trial in Balm. The effectiveness of biofungicides against powdery mildew on cucurbits varies among microbial products. Actinovate AG was tested on muskmelon for suppressing powdery mildew, and had significant effects on disease reduction (8-10). Companion was effective in reducing powdery mildew on summer

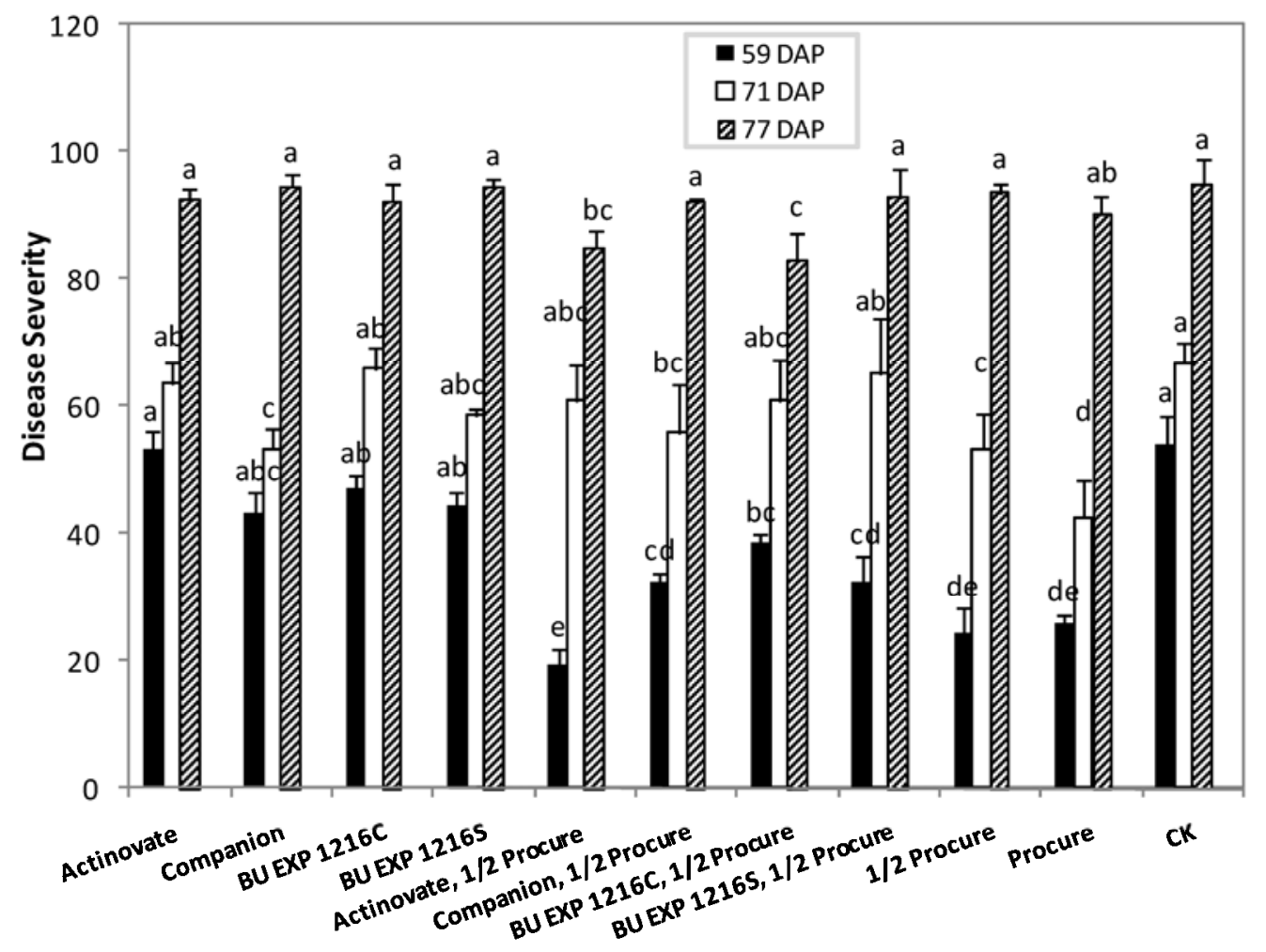

Fig. 3. Efficacy of microbial products applied alone or in alternation with Procure $480 \mathrm{SC}$ on powdery mildew of summer squash 'Medallion' in field trial 2 in Homestead, 2010. The application rate was $2.25 \mathrm{~g} \mathrm{liter}^{-1}$ for Actinovate AG, $6.26 \mathrm{ml} \mathrm{liter}^{-1}$ for Companion, and $9.0 \mathrm{~g} \mathrm{liter}^{-1}$ for both BU EXP 1216C and BU EXP 1216S. Procure 480SC was applied at a low rate of $292 \mathrm{ml} \mathrm{ha}^{-1}$. Treatments were applied once a week for microbial products alone, and once every 2 weeks for each of the microbial products and Procure 480SC in alternating treatments, and for Procure 480SC alone. Disease severity was assessed on five randomly selected plants per plot at 59,71 , and 77 days after planting as the percentage of the leaf surface covered with powdery mildew lesions on fully developed leaves. Means on each rating date followed by the same letter are not significantly different $(P=0.05)$ according to the least significant difference test. Bars represent the standard error of the mean. 
squash (7). In contrast, other studies showed that Actinovate AG was not effective in suppressing powdery mildew disease on summer squash (7) or pumpkin $(5,13)$, especially in terms of controlling powdery mildew on the lower surfaces of leaves. The effect of powdery mildew control by application of biofungicides varies with environmental conditions and other factors such as crop, pathogen, and disease pressure $(18,21)$. Environmental factors which are a common and important concern include humidity, temperature, and intensity of solar radiation. Results from our study showed a similar situation with biofungicides in reduction of powdery mildew on summer squash and cantaloupe under different conditions. The product BU EXP $1216 \mathrm{~S}$ consistently reduced powdery mildew on summer squash in the greenhouse trials (Table 1) but the effect varied under field conditions. Based on AUDPC values, treatment with BU EXP 1216S was effective in suppressing powdery mildew in trial 1 at Balm and Homestead (Tables 2 and 3 ) but not in trial 2. Even though alternating applications of each of the microbial products with Procure 480SC resulted in significant disease reduction in both field trials in Homestead, their efficacies were lower than in the greenhouse experiment. The control efficacy of BU EXP $1216 \mathrm{~S}$ in greenhouse experiments was nearly $70 \%$, whereas its highest efficacy in the field trials was only about $20 \%$. This may be due, at least partly, to greater fluctuations of the environment in the field than in the greenhouse. It has been reported that biofungicides are not as effective as conventional chemical fungicides in controlling powdery mildew because biocontrol agents require higher relative humidity for survival than do powdery mildew pathogens (2).

Based on their studies on powdery mildew in cucurbits, McGrath and Shishkoff (15) suggested that it is important to start application prior to detection of disease symptoms in a protocol managing downy mildew with biofungicides. In field trials conducted in Homestead, levels of disease suppression obtained by applying biofungicides in alteration with a conventional fungicide in trial 1 were greater than in trial 2 . In field trial 1 , bioproduct applications were initiated prior to the occurrence of powdery mildew symptoms whereas, in trial 2, their application was initiated after disease onset. Inappropriate timing of biofungicide applications could be a critical reason for variations in disease suppression in field trials. Despite these complexities, approaches to optimize the use of biofungicides are emerging. In addition to alternating application of biofungicides with conventional fungicides for preventing disease occurrence, applying higher doses, decreasing spray intervals, and switching to conventional chemical fungicides when disease pressure is high could be important and feasible aspects in an improved program for powdery mildew management through the use of biofungicides.

It has been suggested that biofungicides can be effectively incorporated into disease management programs, especially under conditions of high disease pressure, although the biofungicides themselves may be inadequate for disease control when applied exclusively throughout a whole growing season (15). It is very difficult to achieve adequate control of powdery mildew without including a systemic synthetic fungicide. In particular, combining or alternating application of biofungicides with synthetic fungicides can significantly improve levels of powdery mildew disease control (15). Actinovate AG or Companion applied in alternation with synthetic fungicides were found to be effective in suppressing powdery mildew disease on muskmelon $(8,10)$, pumpkin $(1)$, and grape (5). Results from some of our studies are in agreement with the findings from the above studies. In Homestead field trial 1, treatments with biofungicides applied in alternation with Procure 480SC generally had significant effects on disease reduction of powdery mildew at all rating dates (Fig. 2). However, the effect of alternating applications of microbial products with Procure 480SC was significantly improved at the late stage of disease development (i.e., at $88 \mathrm{DAP}$ ) relative to the products or Procure 480SC alone. This effect was also seen in the greenhouse trial 1 with Actinovate AG, Companion, and BU EXP 1216C, each applied in alternation with Procure 480SC (Table 1). In the Balm Field trial 1, this effect was only significant for Companion based on the final disease rating (Table 3). In Balm field trial 2, all of the biopesticides when alternated with Procure 480SC had numerically lower values of

Table 4. Effects of microbial products applied individually or in alternation with Procure $480 \mathrm{SC}$ on powdery mildew severity and yield in cantaloupe in Balm (trial 2, 2010)

\begin{tabular}{llc}
\hline Treatment $^{\mathbf{x}}$ & $\boldsymbol{Y}_{\boldsymbol{f}}^{\mathbf{y}}$ & AUDPC $^{\mathbf{z}}$ \\
\hline Actinovate AG & $49.3 \mathrm{ab}$ & $480 \mathrm{ab}$ \\
Companion & $45.8 \mathrm{ab}$ & $396 \mathrm{ab}$ \\
BU EXP 1216C & $49.3 \mathrm{ab}$ & $446 \mathrm{ab}$ \\
BU EXP 1216S & $36.8 \mathrm{abc}$ & $359 \mathrm{ab}$ \\
Actinovate AG alt. Procure 480SC & $31.2 \mathrm{abc}$ & $243 \mathrm{~b}$ \\
Companion alt. Procure 480SC & $27.5 \mathrm{abc}$ & $250 \mathrm{~b}$ \\
BU EXP 1216C alt. Procure 480SC & $21.7 \mathrm{bc}$ & $215 \mathrm{~b}$ \\
BU EXP 1216S alt. Procure 480SC & $13.1 \mathrm{c}$ & $177 \mathrm{~b}$ \\
Procure 480SC & $36.8 \mathrm{abc}$ & $310 \mathrm{ab}$ \\
Water CK & $54.2 \mathrm{a}$ & $575 \mathrm{a}$ \\
\hline
\end{tabular}

${ }^{w}$ Means within a column followed by the same letter are not significantly different $(P=0.05)$ according to the least significant difference test.

${ }^{x}$ Procure $480 \mathrm{SC}$ was applied at high rates of $584 \mathrm{ml} \mathrm{ha}^{-1}$. Applications were made once every week, except the Procure 480SC-alone treatment and alternating treatments in which either microbial products or Procure 480SC were applied every 2 weeks. Applications were made at 50, 62, 68, and 76 days after planting (DAP).

y $Y_{f}=$ final disease severity. Disease severity was visually rated based on the Horsfall-Barratt scale at 65 and 79 DAP.

${ }^{\mathrm{z}} \mathrm{AUDPC}=$ area under the disease progress curve.

Table 3. Effects of microbial products applied individually or in alternation with Procure 480SC on powdery mildew severity and yield in cantaloupe in Balm (trial 1, 2009)w

\begin{tabular}{|c|c|c|c|c|c|}
\hline \multirow[b]{2}{*}{ Treatment $^{\mathrm{x}}$} & \multicolumn{2}{|c|}{ Powdery mildew } & \multicolumn{3}{|c|}{ Marketable fruit yields } \\
\hline & $Y_{f}^{y}$ & AUDPCz & Total no. (no./plot) & Total wt (kg/plot) & Avg. size (kg/fruit) \\
\hline Actinovate AG & $81.5 \mathrm{ab}$ & $873 \mathrm{bc}$ & $12 \mathrm{~cd}$ & $16.6 \mathrm{bc}$ & $1.42 \mathrm{a}$ \\
\hline Companion & $67.3 \mathrm{~cd}$ & $1,254 \mathrm{~b}$ & 14 abcd & $18.5 \mathrm{abc}$ & $1.34 \mathrm{a}$ \\
\hline BU EXP 1216C & $79.1 \mathrm{bc}$ & $698 \mathrm{bc}$ & $15 \mathrm{abcd}$ & $20.4 \mathrm{abc}$ & $1.41 \mathrm{a}$ \\
\hline BU EXP 1216S & $76.8 \mathrm{bc}$ & $855 \mathrm{bc}$ & $13 \mathrm{bcd}$ & $17.7 \mathrm{abc}$ & $1.36 \mathrm{a}$ \\
\hline Actinovate AG alt. Procure 480SC & $50.0 \mathrm{ef}$ & $480 \mathrm{c}$ & 14 abcd & $18.8 \mathrm{abc}$ & $1.48 \mathrm{a}$ \\
\hline Companion alt. Procure 480SC & $37.5 \mathrm{f}$ & $334 \mathrm{c}$ & $20 \mathrm{a}$ & $25.3 \mathrm{a}$ & $1.27 \mathrm{a}$ \\
\hline BU EXP $1216 \mathrm{C}$ alt. Procure 480SC & $43.8 \mathrm{ef}$ & $380 \mathrm{c}$ & $19 \mathrm{ab}$ & $22.1 \mathrm{ab}$ & $1.21 \mathrm{a}$ \\
\hline BU EXP $1216 S$ alt. Procure $480 S C$ & $56.3 \mathrm{de}$ & $457 \mathrm{c}$ & $18 \mathrm{abc}$ & $24.9 \mathrm{a}$ & $1.29 \mathrm{a}$ \\
\hline Procure $480 \mathrm{SC}$ & $56.3 \mathrm{de}$ & $492 \mathrm{c}$ & $17 \mathrm{abcd}$ & $22.4 \mathrm{ab}$ & $1.44 \mathrm{a}$ \\
\hline Water CK & $93.3 \mathrm{a}$ & $3,315 \mathrm{a}$ & $10 \mathrm{~d}$ & $13.7 \mathrm{c}$ & $1.38 \mathrm{a}$ \\
\hline
\end{tabular}

${ }^{\mathrm{w}}$ Means within a column followed by the same letter are not significantly different $(P=0.05)$ according to the least significant difference test.

${ }^{x}$ Procure $480 \mathrm{SC}$ was applied as high rates of $584 \mathrm{ml} \mathrm{ha}^{-1}$. Applications were made once every week, except the Procure $480 \mathrm{SC}$-alone treatment and alternating treatments in which either microbial products or Procure 480SC were applied every 2 weeks. Applications were made at 34, 41, 48, 55, 62, 69, and 88 days after planting (DAP).

${ }^{\text {y }} Y_{f}=$ final disease severity. Disease severity was visually rated based on the Horsfall-Barratt scale at 68 and 83 DAP.

${ }^{\mathrm{z}}$ AUDPC $=$ area under the disease progress curve. 
AUDPC than Procure 480SC alone (Table 4), but these differences were not significant. Considering the benefit from an economic and environmentally safe standpoint, growers who do not want to rely on conventional fungicides could use biopesticides for control of powdery mildew exclusively when disease pressure is low but will need to apply a biofungicide in rotation with a conventional fungicide under conditions of high disease pressure. A possible theoretical approach is to apply biologically based products until the disease pressure reaches a threshold, then switch to the alternating use of a conventional fungicide when disease pressure increases or when conditions become more favorable for disease. Further research is needed to establish this theoretical threshold and document that this approach could be effective.

\section{Acknowledgments}

This research was supported in part by a grant from IR-4. We thank Seminis Vegetable Seeds, Oxnard, CA for providing seed of squash (Goldbar) used in greenhouse assays, and R. See at Seedway-SE Florida and T. Menendez at Howard Fertilizers in Homestead, FL for donating seed for the field trials.

\section{Literature Cited}

1. Bay, I. S., Janousek, C. N., Herche, R. W., and Gubler, W. D. 2010. Management of cucurbit powdery mildew with organic and synthetic fungicides, 2009. Plant Disease Management Reports 4: V085. Online publication. doi: 10.1094/PDMR04.

2. Bélanger, R. R., and Avis, T. J. 2002. Ecological processes and interactions occurring in leaf surface fungi. Pages 193-207 in: Phyllosphere Microbiology. S. E. Lindow, E. I. Hecht-Poinar, and V. J. Elliott, eds. American Phytopathological Society, St. Paul, MN.

3. Dhatt, M. S., Iqbal, J., and Gubler, W. D. 2001. Evaluation of fungicides for control of grapevine powdery mildew trial 4, 2000. Fungic. Nematicide Tests 56: SMF 15. Online publication. doi: 10.1094/FN56.

4. Janousel, C. N., Bay, I. S., and Gubler, W. D. 2008. Bacterial control of grape powdery mildew, 2007. Plant Disease Management Reports 2: SMF053. Online publication. doi: 10.1094/PDMR02.

5. Janousel, C. N., Bay, I. S., and Gubler, W. D. 2010. Evaluation of Actinovate and AMV-4024 (caprylic acid) for powdery mildew management in grape, 2009. Plant Disease Management Reports 4: SMF010. Online publication. doi: 10.1094/PDMR04.

6. Jarvis, W. R., Shaw, L. A., and Traquair, J. A. 1989. Factors affecting antagonism of cucumber powdery mildew by Stephanoascus flocculosus and S. rugulosus. Mycol. Res. 92:162-65.

7. Langston, D. B., Jr., and Sanders, F. H., Jr. 2009. Evaluation of selected fungicides for control of powdery mildew in summer squash in Georgia,
2008. Plant Disease Management Reports 3: V149. Online publication. doi: 10.1094/PDMR03.

8. Matheron , M. E., and Porchas, M. 2008. Comparison of fungicides for management of powdery mildew on muskmelon, 2007. Plant Disease Management Reports 2: V085. Online publication. doi: 10.1094/PDMR02.

9. Matheron , M. E., and Porchas, M. 2009. Comparison of fungicides for management of powdery mildew on muskmelon, 2008. Plant Disease Management Reports 3: V102. Online publication. doi: 10.1094/PDMR03.

10. Matheron, M. E., and Porchas, M. 2010. Comparing efficacy of fungicides for management of powdery mildew on muskmelon, 2009. Plant Disease Management Reports 4: V050. Online publication. doi: 10.1094/PDMR04.

11. McGrath, M. T., 1996. Increased resistance to triadimefon and to benomyl in Sphaerotheca fuliginea populations following fungicide use over one season. Plant Dis. 80:633-639.

12. McGrath, M. T. 1996. Successful management of powdery mildew in pumpkin with disease threshold-based fungicide programs. Plant Dis. 80:910-916.

13. McGrath, M. T., and Davey, J. F. 2007. Evaluation of biofungicides for managing powdery mildew of pumpkin, 2006. Plant Disease Management Reports 1: V145. Online publication. doi: 10.1094/PDMR01.

14. McGrath, M. T., and Fox, G. M. 2009. Evaluation of biofungicides for managing foliar diseases in organically-produced tomato, 2008. Plant Disease Management Reports 3: V127. Online publication. doi: 10.1094/ PDMR03.

15. McGrath, M. T., and Shishkoff, N. 1999. Evaluation of biocompatible products for managing cucurbit powdery mildew. Crop Prot. 18:471-478.

16. McGrath, M. T., Staniszewska, H., Shishkoff, N., and Casella, G. 1996 Fungicide sensitivity of Sphaerotheca fuliginea populations in the United States. Plant Dis. 80:697-703.

17. McGrath, M. T., and Thomas, C. E. 1996. Powdery mildew. Pages 28-30 in: Compendium of Cucurbit Diseases. T. A. Zitter, D. L. Hopkins, and C. E. Thomas, eds. American Phytopathological Society, St. Paul, MN.

18. Nuñez-Palenius, H. G., Hopkins, D., and Cantliffe, D. J. 2006. Powdery Mildew of Cucurbits in Florida. Available at http://edis.ifas.ufl.edu/hs321.

19. O'Brien, R. G., Vawdrey, L. L., and Glass, R. J. 1988. Fungicide resistance in cucurbit powdery mildew (Sphaerotheca fuliginea) and its effect on field control. Aust. J. Exp. Agric. 28:417-423.

20. Olson, S. M., Simonne, E. H., Stall, W. M., Roberts, P. D., Webb, S. E., Taylor, T. G., Smith, S. A., and Freeman, J. H. 2009. Cucurbit Production in Florida. Pages 77-106 in: Vegetable Production Handbook for Florida 2009 2010. S. M. Olson and E. H. Simonne, eds. Florida Cooperative Services, University of Florida.

21. Paulitz, T. C., and Belanger, R. R. 2001. Biological control in greenhouse systems. Annu. Rev. Phytopathol. 39:103-133.

22. Su, H., and Gubler, W. D. 2007. Evaluation of fungicides for controlling powdery mildew in strawberry in California, 2006. Plant Disease Management Reports 1: SMF022. Online publication. doi: 10.1094/PDMR01. 